\title{
CLOSER COLLABORATION BETWEEN DIFFERENT MENTAL HEALTH SERVICES FOR GOOD OUTCOMES FOR PEOPLE WITH MENTAL DISORDERS
}

\author{
G. Racetovic $^{1}$, M. Latinovic ${ }^{2}$, S. Popovic ${ }^{3}$, S. Grujic-Timarac ${ }^{4}$, B. Rosic ${ }^{3}$ \\ ${ }^{1}$ Health Center, Community Mental Health Center,Prijedor; \\ ${ }^{2}$ Ministry of Health and Social Welfare of Republic of Srpska, Sector for Hospital Health Care, Banja Luka; \\ ${ }^{3}$ Health Centre Prijedor, Management of the HC Prijedor, Prijedor; \\ ${ }^{4}$ Hospital "Dr. Mladen Stojanovic" Prijedor, Department for Psychiatry, Prijedor, Republic of Srpska/Bosnia and Herzegovina
}

Objectives: In the last 5 years Republic of Srpska (and Bosnia and Herzegovina as well) established new model of providing of quality of services in primary and secondary health care using certification and accreditation standards. Special importance has been given to improvement of mutual and closer collaborations between community mental health center and hospital/clinical departments of psychiatry.

Background and Aims: As importance of providing of quality services in treatment and rehabilitation of users in all mental health institutions is primary role of all mental health professionals, closing mutual collaboration's protocols was one of the way to accomplish that aims. This paper will try to show possibilities, advantages as well obstacles in the implementation of these processes.

Materials and Methods: For preparation of this lecture were used books of standards for health institutions and accreditation standards for CMHCs in Republic of Srpska and comparative method of their practical implementation as well influence for better quality of life of mutual users.

Results: In the last 5 years in the Republic of Srpska most of 27 CMHCs are accredited and established additional standards in their work. Hospital/clinical departments (one Clinic for Psychiatry, two Hospitals for chronic Psychiatry, one Institute for Forensic Psychiatry and 6 hospital departments) did not achieve accreditation and less number has official certificates but using standards in daily work.

Conclusions In general, mutual collaboration is not adequate even there are potentials for improvements: case management approaches, occupational therapy, group therapies, home visits, counseling, etc. All this community services can be bounding issues between hospital and CMHC for continuous rehabilitation in home and natural environment of patients and connections with all other existing services in community.

Future activities in implementation of the Model of joint discharge from the hospital and creation of new Law of Mental Health of Republic of Srpska are first steps to accomplish this aims.

Keywords: Collaboration, Quality, Community, Mental Health, Hospital.

Conflict of interests:

Authors did not declare any conflict of interests.

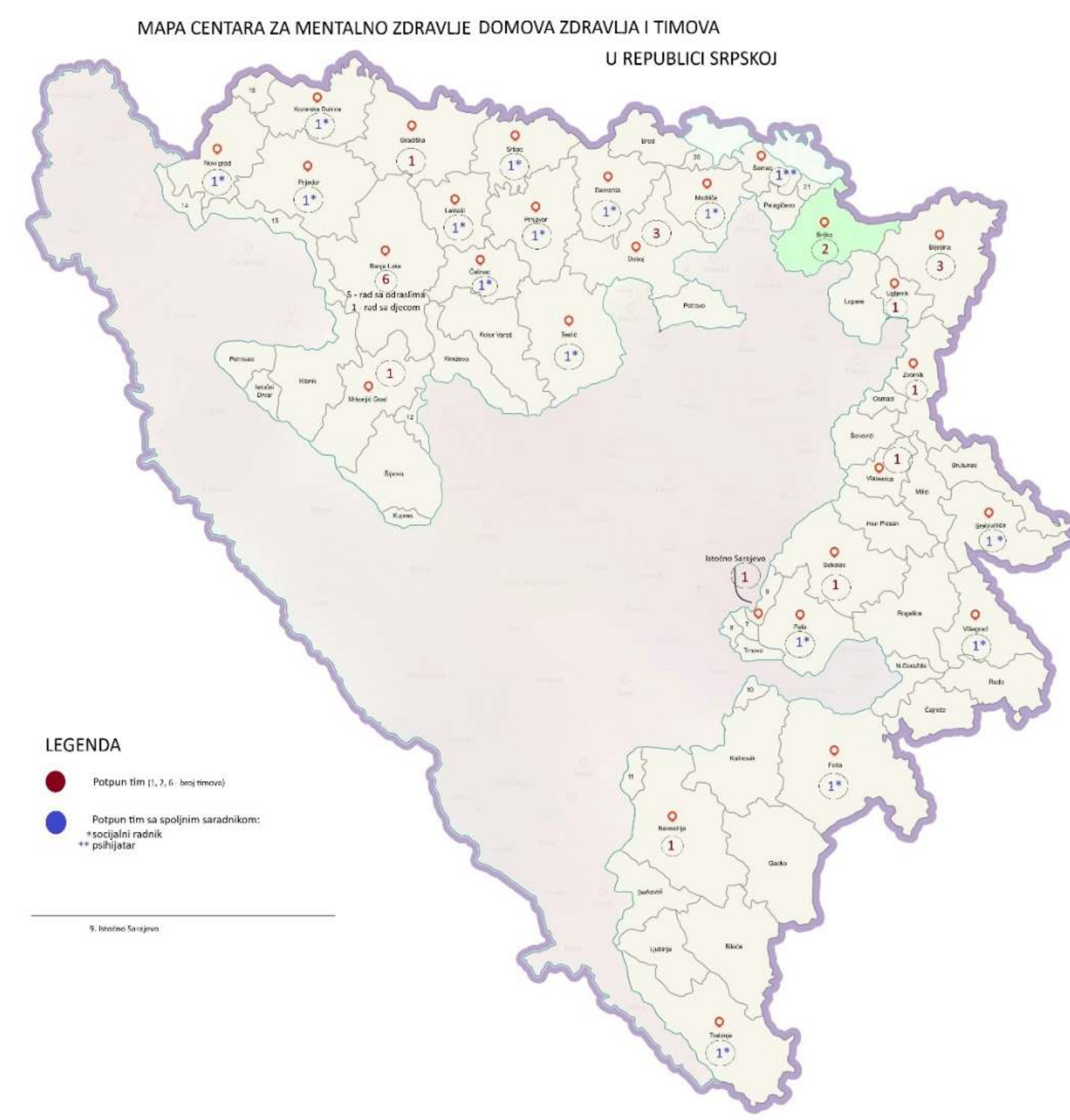

Picture 1.

Network of the CMHC in Republic of Srpska 